\title{
EXERGY ANALYSIS AND EXERGOECONOMIC OPTIMIZATION OF A BINARY CYCLE SYSTEM USING A MULTI OBJECTIVE GENETIC ALGORITHM
}

\author{
Nasruddin $^{1 *}$, Syaiful Nasution ${ }^{1}$, Nyayu Aisyah ${ }^{1}$, Arief Surachman $^{1}$, Agung Satrio Wibowo $^{1}$ \\ ${ }^{1}$ Department of Mechanical Engineering, Faculty of Engineering, Universitas Indonesia, Kampus UI \\ Depok, Depok 16424, Indonesia
}

(Received: December 2017 / Revised: December 2017 / Accepted: January 2018)

\begin{abstract}
The increasing demand for energy and the current environmental issues are motivating experts to develop appropriate technology to face both problems. The binary cycle system is a highly effective generating technology which can be applied in the utilization of small-scale geothermal energy by using a working fluid that has a lower boiling point than water. In this paper, a geothermal power plant binary cycle system model was tested by using waste brine at a temperature of $180^{\circ} \mathrm{C}$ at well pad 4 of the Dieng geothermal power plant. In the optimization procedure, total exergy destruction and total annual cost are chosen as the objective functions. Optimization is made by using a multi objective genetic algorithm. Based on the simulation, it is known that the exergy efficiency and economic value of the optimal binary cycle of the geothermal power plant system has optimum conditions at an evaporation temperature of $163.3^{\circ} \mathrm{C}$, a brine temperature in the preheater outlet of $130^{\circ} \mathrm{C}$, and a water cooling temperature at condenser outlet of $35.4^{\circ} \mathrm{C}$. The working fluid pressure at pump outlet is $3859 \mathrm{kPa}$ with the composition of the working fluid mixture being $86 \%$ R601 and 14\% R744, resulting in turbine power of $119.8 \mathrm{~kW}$, total exergy destruction of $742.4 \mathrm{~kW}$, and a total annual cost of 36,723 US dollars. These results indicate that, by setting the above operating conditions, the system can achieve optimum efficiency, as indicated by the minimum values of both exergy destruction and total annual cost.
\end{abstract}

Keywords: Binary cycle system; Cost; Exergy destruction; Exergy efficiency; Genetic algorithm

\section{INTRODUCTION}

The world is currently experiencing environmental problems, especially climate change caused of global warming. One of this is the occurrence of the greenhouse effect from the carbon dioxide $\left(\mathrm{CO}_{2}\right)$ emissions generated by uncontrolled use of fossil fuels. The rapid development of industry today results in higher energy consumption. To overcome this problem, various resources of large potential renewable energies have been used and still being developed in Indonesia such as solar energy and geothermal. The application of solar energy for absorption and adsorption cooling systems have been developed at Universitas Indonesia (Lubis et al. 2018 and Nasruddin et al. 2015). Meanwhile, it is estimated that $40 \%$ of world geothermal energy reserves exist in Indonesia. Compared to the total potential that exists, geothermal energy utilization in Indonesia is still very low, at $1.4 \mathrm{GW}$ or only $4.5 \%$ of the existing potential (Nasruddin et al., 2016a). The Organic Rankine Cycle (ORC) is a power plant system that uses

*Corresponding author's email: nasruddin@eng.ui.ac.id, Tel: +62-21-7270032, Fax: +62-21-7270033

Permalink/DOI: https://doi.org/10.14716/ijtech.v9i2.1040 
organic fluids. It is estimated that there will be around $10 \%$ additional power in the power generation in the main ORC system (Prasetyo et al., 2010).

Study of the selection of the best working fluids for thermal systems has been conducted by Budisulistyo and Krumdieck. They investigated a pre-FS design of binary cycles with three types of working fluid, n-pentane, R245fa and R134a. Their results showed that the use of npentane resulted in greater output power and thermal efficiency compared to use of the other working fluids (Budisulistyo \& Krumdieck, 2015).

Systems with pure working fluids have a limitation on isothermal boiling, which causes poor heating between working fluids and heat sources on pinch points, that producing major irreversibility (Chen et al., 2011). Therefore, the use of mixed working fluids can be solution to this problem (Chen et al., 2006). Wu et al. (2017) conducted a study by performing thermodynamic analysis and performance optimization of geothermal power plant using six types of working fluids, with each mixed with $\mathrm{CO}_{2}$. Their results showed that the mixture of $\mathrm{R} 161$ with $\mathrm{CO}_{2}$ was the best working fluid in terms of thermal efficiency and cost. The selected $\mathrm{CO}_{2}$-based mixture can reduce the cost per $\mathrm{kWh}$ even though larger areas of heat acquisition are required. With regard to refrigeration system, Nasruddin et al. (2016b) successfully conducted optimization scenario of a cascade refrigeration system by using refrigerant $\mathrm{C}_{3} \mathrm{H}_{8}$ in high temperature circuits and a mixture of $\mathrm{C}_{2} \mathrm{H}_{6} / \mathrm{CO}_{2}$ in low temperature circuits. Garg et al. (2013) evaluated the $\mathrm{CO}_{2}$ mixture with isopentane and propane in an ORC system by utilizing solar energy. The results showed an increase of pressure and a larger temperature glide, which the mixture of isopentane with $\mathrm{CO}_{2}$ had greater irreversibility compared to the propane mixture with $\mathrm{CO}_{2}$. Dai et al. (2014) performed thermodynamic analysis by mixing $\mathrm{CO}_{2}$ with seven types of working fluids. The simulation results showed that the R1234yf / $\mathrm{CO}_{2}$ mixture was suitable for large capacity transcritical power cycles due to its lower burnability and increased thermal and exergy efficiency compared to pure $\mathrm{CO}_{2}$.

The purpose of this study is to increase the efficiency and sustainability of Dieng geothermal power plant and its decrease the environmental effect such as global warming by also considering the cost of the binary cycle system. Therefore, the paper presents an exergy analysis of the system by using an environmentally friendly working fluid, an R601 and R744 mixture. This mixture is selected because R601 is a natural working fluid that has a high critical temperature up to $196^{\circ} \mathrm{C}$, non-toxic and does not damage the atmospheric layer or contribute to global warming. However, since R601 belongs to the flammable hydrocarbon group, R744 is added with the aim of reducing the flammable properties of R601. The originality of this work is the attempt to achieve the optimum operating conditions of the binary cycle system by using a multi-objective optimization study based on exergy and the economic point of view. This optimization scenario is based on a code developed in Matlab software which is also integrated with REFPROP software. As a result, a balance between system performance and the total cost of the system can be achieved and optimum system conditions obtained.

\section{METHODOLOGY}

\subsection{Exergy Analysis}

Thermodynamic analysis is applied in the analysis of exergy, because it will be able to analyze the energy losses of the components and sub systems. Consequently, a method to reduce system losses can be developed which will ultimately be able to improve exergy efficiency. The thermodynamic analysis of the binary cycle system was performed using MATLAB software with the following assumptions:

1. The system operates at steady state, thermodynamic equilibrium conditions exist for all the states and the kinetic and potential energies are neglected; 
2. The work of the pump and turbine is isentropic and with efficiencies of $70 \%$ and $85 \%$, respectively.

3. The pressure and heat loss in the system pipe lines are neglected;

4. The refrigerant is saturated at the condenser and evaporator outlets.

The binary cycle system of the geothermal power plant scheme is further described in Figure 1.

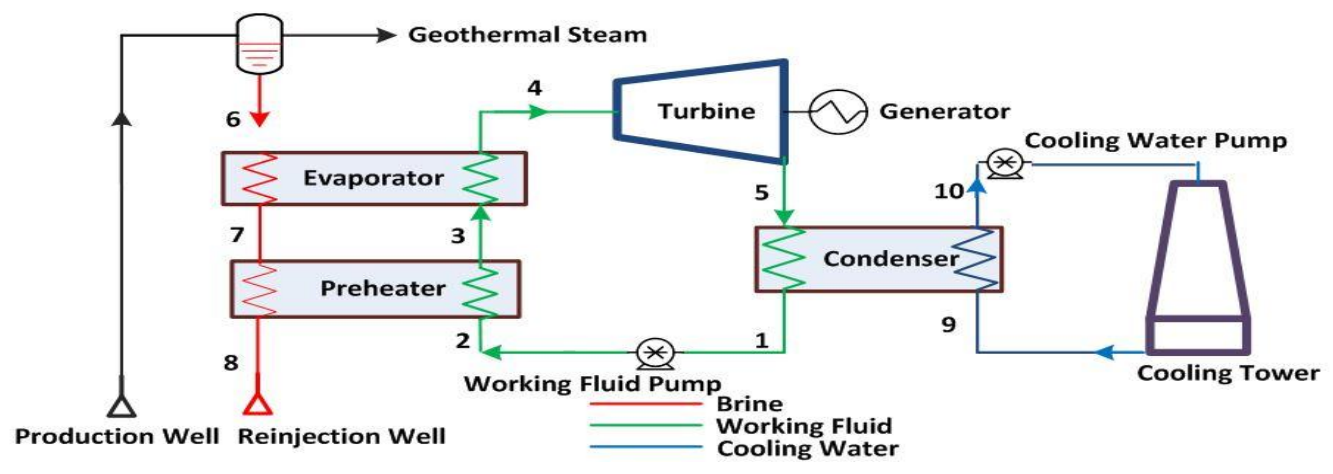

Figure 1 Schematic diagram of the binary cycle system

By using the state points shown in Figure 1 equilibrium equations for each component of the system are shown in Table 1.

Table 1 Equilibrium equations for each component of the system

\begin{tabular}{|c|c|c|c|}
\hline Component & Mass & Energy & Exergy destruction \\
\hline Working fluid pump & $\dot{m}_{1}=\dot{m}_{2}=\dot{m}_{f}$ & $\dot{W}_{p f}=\dot{m}_{f}\left(h_{2}-h_{1}\right)$ & $\vec{E} x_{\text {dest }}=\dot{W}_{p f}-\left(\dot{E} x_{2}-\dot{E}_{x_{1}}\right)$ \\
\hline Preheater & $\begin{array}{l}\dot{m}_{2}=\dot{m}_{3}=\dot{m}_{f} \\
\dot{m}_{7}=\dot{m}_{B}=\dot{m}_{b}\end{array}$ & $\dot{m}_{b}\left(h_{7}-h_{B}\right)=\dot{m}_{f}\left(h_{3}-h_{2}\right)$ & $\mathrm{E}_{\mathrm{x}_{\text {dest }}}=\left(\mathrm{E}_{\mathrm{x}_{2}}^{\prime}+\mathrm{E}_{\mathrm{x}_{7}}^{\prime \prime}\right)-\left(\mathrm{Ex}_{\mathrm{g}}+\mathrm{E}_{\mathrm{x}_{\mathrm{B}}}^{\prime}\right)$ \\
\hline Evaporator & $\begin{array}{l}\dot{m}_{3}=\dot{m}_{4}=\dot{m}_{f} \\
\dot{m}_{6}=\dot{m}_{7}=\dot{m}_{b}\end{array}$ & $\dot{m}_{b}\left(h_{6}-h_{7}\right)=\dot{m}_{f}\left(h_{4}-h_{9}\right.$ & $\mathrm{Ex}_{\text {dest }}=\left(\mathrm{Ex}_{1}+\mathrm{Ex}_{6}\right)-\left(\mathrm{Ex}_{4}+\mathrm{Ex}_{7}\right)$ \\
\hline Turbine & $\dot{m}_{4}=\dot{m}_{5}=\dot{m}_{f}$ & $\dot{W}_{\text {tur }}=\dot{m}_{f}\left(h_{4}-h_{5}\right)$ & $\vec{E} x_{d e s t}=\left(\dot{E} x_{4}-\dot{E} x_{5}\right)-W_{t u r}$ \\
\hline Condenser & $\begin{array}{l}\dot{m}_{5}=\dot{m}_{1}=\dot{m}_{f} \\
\dot{m}_{9}=\dot{m}_{10}=\dot{m}_{o w}\end{array}$ & $\dot{m}_{w W}\left(h_{9}-h_{10}\right)=\dot{m}_{f}\left(h_{5}-h_{1}\right.$ & $\mathrm{E}_{\mathrm{x}_{\text {dest }}}=\left(\mathrm{Ex}_{5}+\mathrm{E}_{x_{9}}\right)-\left(\mathrm{Ex}_{1}+\mathrm{Ex}_{10}\right)$ \\
\hline Cooling water pump & $\dot{m}_{9}=\dot{m}_{10}=\dot{m}_{e W}$ & $\dot{W}_{\text {ewp }}=\dot{m}_{e w}\left(h_{10}-h_{g}\right)$ & $E x_{\text {dest }}=W_{\text {exp }}-\left(E x_{10}-E x_{q}\right)$ \\
\hline
\end{tabular}

The mass flow rate of the working fluid in the evaporator is defined as:

$$
\dot{m_{f}}=\frac{Q_{\text {gvap }}}{\left(h_{4}-h_{g}\right)}
$$

where $Q_{\text {evap }}$ is obtained from the following equation:

$$
Q_{\text {evap }}^{*}=\dot{m}_{b}\left(h_{6}-h_{7}\right)
$$

To establish the exergy destruction for each component and the whole system, the basic formula of exergy rate analysis is used as follows (Pambudi et al., 2014):

$$
\dot{E}_{x, n}=\dot{m}\left(h-h_{0}-T_{\circ}\left(s-s_{\circ}\right)\right)
$$


Total exergy destruction of the system is written as follows:

$$
\dot{E} x_{\text {desstotal }}=\dot{E} x_{\text {des.ph }}+\dot{E} x_{\text {dessevap }}+\dot{E} x_{\text {des.tur }}+\dot{E} x_{\text {desicon }} \dot{E} x_{\text {des.pf }}+\dot{E} x_{\text {des.pew }}
$$

The comparison between the expected exergy output (product) against the potential exergy used is called the exergy efficiency ratio expressed as (DiPippo, 2007):

$$
\eta_{e x}=\frac{E x_{\text {out }}}{E x_{\text {in }}}=1-\frac{E x_{\text {des }} \text { total }}{\left(E^{\prime} x_{6}+W_{\text {ewp }}+W_{p f}\right)}
$$

\subsection{Heat Exchanger Modeling}

The working fluid entering the evaporator is usually in a two-phase state, and will evaporate until it reaches the saturation state. The equation for calculating the Reynold number on the water side is:

$$
R e=\frac{G_{w} d_{h}}{\mu_{w}}
$$

where $G_{w}$ is mass flux, $\mathrm{d}_{\mathrm{h}}$ is hydroulic diameter and $\mu_{w}$ is fluid viscosity in this case of water. The equation that is used to calculate the Nuselt number as follows (Sachdeva, 2006):

$$
N u=0.122 P r^{\frac{1}{3}}\left(f e^{2} \sin (2 \beta)\right)^{0.374}
$$

which $R e$ is a Reynold number and $P r$ is a Prandtl number, $f$ is the friction factor and $\beta$ is the chevron angle. The heat transfer coefficient on the water side can therefor be calculated by the equation:

$$
h_{w}=\frac{N u k_{w}}{d_{h}}
$$

where $k_{w}$ is thermal conductivity. The heat transfer on the working fluid side uses an equation that refers to the correlation (Longo et al., 2015):

$$
h_{w f}=0.122 \frac{k_{r e f}}{d_{h 2}} \operatorname{Re}^{0.8} \operatorname{Pr}^{1 / 3}
$$

Furthermore the overall heat transfer coefficient for the evaporator is calculated by the equation:

$$
U=\frac{1}{\left[\left(\frac{1}{h w}\right)+\left(\frac{t}{k}\right)+\left(\frac{1}{h w f}\right)\right]}
$$

The required area (A) can be determined by the equation:

$$
A=\frac{Q}{\text { ULMTD }}
$$


where $\mathrm{A}$ is the area, $\mathrm{Q}$ is the energy received by the evaporator, $\mathrm{U}$ is the overall heat transfer coefficient and LMTD is a function of the temperature at the evaporator whose LMTD values can be obtained from the equation:

$$
L M T D=\frac{T_{a}-T_{b}}{\ln \left(\frac{T_{a}}{T_{b}}\right)}
$$

Calculation of the Nusselt number condenser for water side is made by (Longo et al., 2015):

$$
N u=0.332 \operatorname{Re}^{1 / 2} \operatorname{Pr}^{1 / 3}
$$

And calculation of the heat transfer coefficient for the working fluid side by (Sachdeva, 2006) :

$$
h_{r e f}=1.875 \frac{k_{r e f}}{d_{h \mathfrak{h}}} \operatorname{Re}^{0.445} \operatorname{Pr}^{1 / 3}
$$

The following calculation is the value of $U$ and $A$ in the evaporator.

\subsection{Economic Analysis}

Before deciding to make an investment after conducting a technical review, one of the most important requirements is to examine the financial and economic aspects. Two economic factors on this paper, namely the initial investment price and the operational and maintenance costs of each component when the system is run for a predetermined period of time. The equations and variables used in determining the purchase price and the operational costs of a component are flexible. This means they can change over time depending on the dynamics of the economic conditions and other influencing factors. The assumptions to facilitate the calculation are as follows:

1. System lifetime (n) of 20 years.

2. Total operating time $(\mathrm{H})$ of 8766 hours per year.

3. Interest rate (i) of $12 \%$.

4. Installation factor (if) of $1.5 \%$ of capital cost.

5. The annual operational and maintenance costs for generating a capacity of $0.05 \mathrm{MW}-0.25$

MW are assumed to be $7 \%$ of the initial investment cost (Taylor, 2015).

The investment cost in this paper is refrers to the cost of purchasing the main equipment and its installation. The following equations are used for calculating the main equipment cost components (Taylor, 2015):

$$
\begin{gathered}
\mathrm{C}_{H E}=1140 \times A_{0, H E}^{0.691} \times \text { If } \\
\mathrm{C}_{\text {turbin }}=1360 \times W_{\text {tur }}{ }^{0.81} \times \text { If } \\
\mathrm{C}_{g e n}=225 \times W_{\text {tur }}{ }^{0.81}+875 \times \text { If }
\end{gathered}
$$

where $\mathrm{C}_{H E}$ is the cost of the heat exchanger, $\mathrm{A}_{0}$ is the heat exchanger area, $C_{\text {turbin }}$ is the cost of the turbine, $\mathrm{W}_{\text {tur }}$ is the work of the turbine and $\mathrm{C}_{\text {gen }}$ is the cost of the generator. Based on the equations to calculate the cost of main components above, the capital cost of the system is:

$$
\text { Capital }_{\text {cost }}=\left(C_{\text {turbin }}+C_{\text {gen }}+C_{\text {cond }}+C_{\text {evap }}+C_{p h}\right)
$$

The annual operating and maintenance costs $(\mathrm{OM})$ are calculated as follows:

$$
O M_{\text {cost }}=O M_{\text {factor }} x C_{\text {total }}
$$


By connecting Equations 18 and 19 is possible to obtain the value of the total annual cost (TAC) to be incurred as follows:

$$
T A C=\text { Capital }_{\text {cost }} x C R F+O M_{\text {cost }}
$$

which the CRF variable is a Capital Recovery Factor that is a factor of return on capital from the cost of purchasing components per year and declared as (Bejan, 1989):

$$
C R F=\frac{i *(1+i)^{n}}{(1+i)^{n}-1}
$$

\subsection{Optimization Procedure}

The focus of this paper is to establish the optimum value by combining cost and exergy analysis. The binary cycle system optimization procedure is shown in Figure 2.

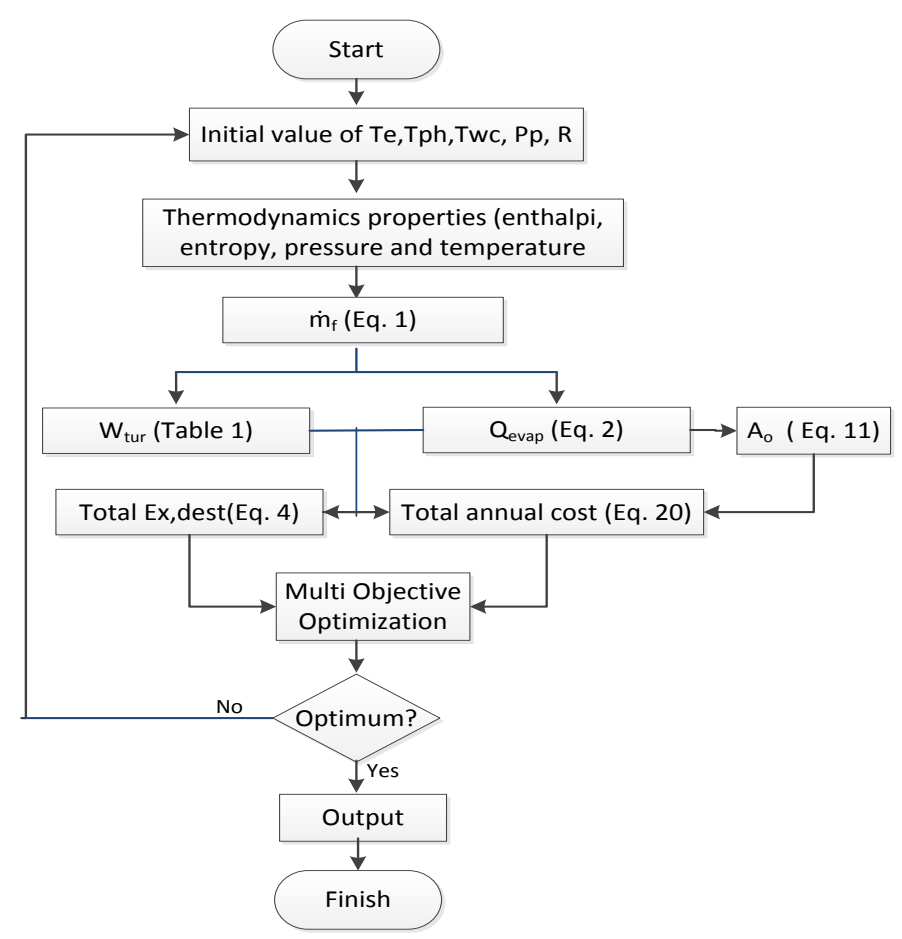

Figure 2 Optimization flow diagram system

The parameters in the optimization with the genetic algorithm have a population size of 70 , a Pareto front population fraction of 0.7 , and a 1000 generation and function tolerance of $10^{-4}$. The system boundaries for optimization are shown in Tables 2 and 3.

Table 2 Constraints of the system

\begin{tabular}{clcc}
\hline No & \multicolumn{1}{c}{ Parameter } & Unit & Value \\
\hline 1 & Brine inlet temperature at evaporator $\left(\mathrm{T}_{6}\right)$ & ${ }^{\circ} \mathrm{C}$ & 180 \\
2 & Brine inlet temperature at preheater $\left(\mathrm{T}_{7}\right)$ & ${ }^{\circ} \mathrm{C}$ & 140 \\
3 & Pinch point outlet temperature at condenser & ${ }^{\circ} \mathrm{C}$ & 10 \\
4 & Working fluid outlet temperature at pump $\left(\mathrm{T}_{2}\right)$ & ${ }^{\circ} \mathrm{C}$ & 32.4 \\
5 & Working fluid outlet temperature at preheater $\left(\mathrm{T}_{3}\right)$ & ${ }^{\circ} \mathrm{C}$ & 48 \\
6 & Working fluid outlet temperature at turbine $\left(\mathrm{T}_{5}\right)$ & ${ }^{\circ} \mathrm{C}$ & 130 \\
\hline
\end{tabular}


Table 3 System limits for optimization procedure

\begin{tabular}{clccc}
\hline No & \multicolumn{1}{c}{ Parameter } & Unit & From & To \\
\hline 1. & Working fluid outlet temperature at evaporator $\left(\mathrm{T}_{4}\right)$ & ${ }^{\circ} \mathrm{C}$ & 163 & 170 \\
2. & Brine outlet temperature at preheater $\left(\mathrm{T}_{8}\right)$ & ${ }^{\circ} \mathrm{C}$ & 125 & 135 \\
3. & Water cooling outlet temperature at condenser $\left(\mathrm{T}_{10}\right)$ & ${ }^{\circ} \mathrm{C}$ & 33 & 43 \\
4. & Working fluid outlet pressure at pump $\left(\mathrm{P}_{2}\right)$ & $\mathrm{kPa}$ & 3800 & 4000 \\
5. & Working fluid mixed fraction $(\mathrm{R})$ & $\%$ & 0.01 & 0.3 \\
\hline
\end{tabular}

\section{RESULTS AND DISCUSSION}

\subsection{Influence of Mixed Working Fluid Fraction}

The effect of the fraction of the addition of R744 to R601 on total exergy destruction and the total annual cost of the system can be seen in Table 4, Figures 3 and 4.

Table 4 Effect of Working Fluid Mixed Mass Fraction (R601 + R744)

\begin{tabular}{lccccccccc}
\hline \multirow{2}{*}{ Parameter } & \multirow{2}{*}{ Unit } & \multicolumn{7}{c}{ Mass Fraction of R744 (\%) } \\
\cline { 3 - 9 } & & 0.01 & 0.05 & 0.1 & 0.14 & 0.15 & 0.2 & 0.25 & 0.3 \\
\hline Wtur & $\mathrm{kW}$ & 59.7 & 70.9 & 95.6 & 119.8 & 123.0 & 148.3 & 172.4 & 194.1 \\
APH & $\mathrm{m}^{2}$ & 21.8 & 21.8 & 21.8 & 21.8 & 21.8 & 21.8 & 21.8 & 21.8 \\
Aevap & $\mathrm{m}^{2}$ & 35.1 & 35.4 & 37.9 & 41.0 & 41.5 & 45.1 & 48.7 & 48.8 \\
Acond & $\mathrm{m}^{2}$ & 28.1 & 28.1 & 28.1 & 28.1 & 28.1 & 28.1 & 28.1 & 28.1 \\
Eff. exergy & $\%$ & 46.5 & 47.2 & 48.0 & 48.8 & 48.8 & 49.5 & 50.1 & 50.6 \\
Total ex, dest & $\mathrm{kW}$ & 779.1 & 767.7 & 753.3 & 742.4 & 740.9 & 729.7 & 720.2 & 712.2 \\
Total annual cost & US \$ & 24,863 & 27,109 & 32,012 & 36,723 & 37,348 & 42,128 & 46,589 & 50,292 \\
\hline
\end{tabular}

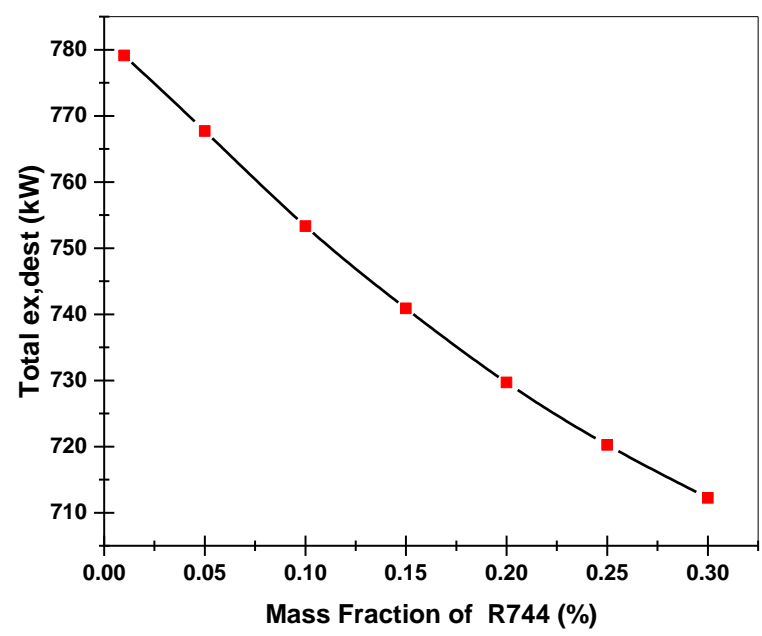

Figure 3 Effect of R744 mass fraction on total exergy destruction

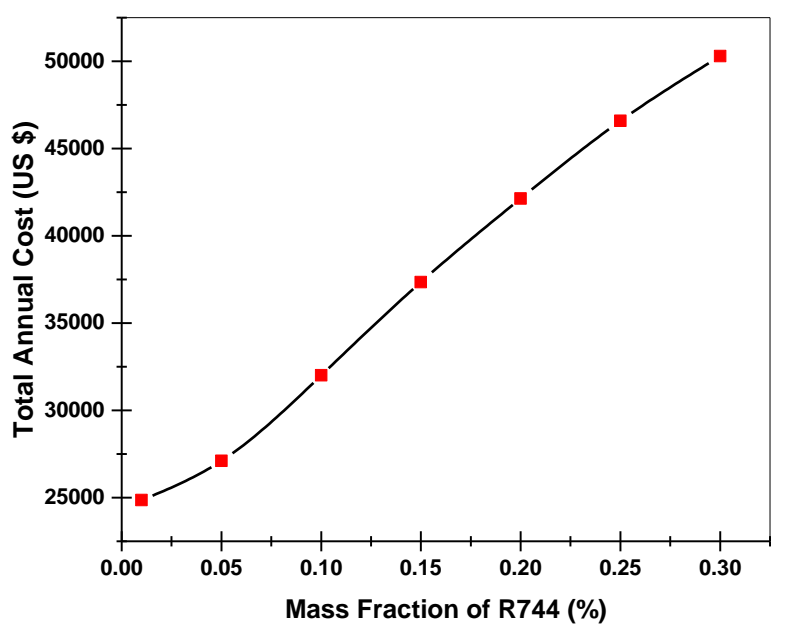

Figure 4 Effect of R744 mass fraction on total annual cost

Figure 3 shows the effect of changes in the mass fraction of the working fluid R744 on the total exergy destruction obtained from the multi objective optimization results between total cost and total exergy destruction. Based on the result of the simulation, it is established that the mass fraction R744 has the smallest total exergy destruction of $30 \%$. The largest total exergy destruction is obtained at a fraction of the R744 volume of $1 \%$. With an increasing level of mass fraction R744 on R601, the total exergy destruction of the system will decrease. This is caused by the increase of pressure that causes the system will produce greater work so that the exergy efficiency also increases. The effect of changes in the mass fraction of R744 on the total annual cost can be seen in Figure 4. From the simulation conducted, it is seen that the highest system cost occurs when the R744 mass fraction is $30 \%$ and the lowest cost occurs when the $\mathrm{R} 744$ volume fraction is $1 \%$. 
The addition of R744 volume fraction causes an increase in the total annual cost. This is due to the mixing of the two working fluids, so the thermodynamic properties of the working fluid undergo changes in both evaporation and condensation temperatures and enthalpic value which will directly result in the changes to the total annual cost.

\subsection{Multi Objective Optimization of the Binary Cycle System}

Table 5 shows the results of the three optimizations performed using single objective cost, single objective exergy destruction and multi objective which considers both of exergy destruction and cost.

Table 5 Results of single objective and multi objective optimization

\begin{tabular}{|c|c|c|c|c|}
\hline Parameter & Unit & Termodynamic & Multi Objective & Economic \\
\hline $\mathrm{T}_{\text {evapo }}$ & ${ }^{\circ} \mathrm{C}$ & 169.7 & 163.3 & 163 \\
\hline $\mathrm{T}_{\text {bpo }}$ & ${ }^{\circ} \mathrm{C}$ & 130.9 & 130 & 133.9 \\
\hline $\mathrm{T}_{\text {condo }}$ & ${ }^{\circ} \mathrm{C}$ & 38.3 & 35.4 & 35 \\
\hline $\mathrm{P}_{\text {pump }}$ & $\mathrm{kPa}$ & 3820 & 3859 & 3815 \\
\hline Mixed Fraction & $\%$ & 29 & 14 & 1.5 \\
\hline \multicolumn{5}{|l|}{ System } \\
\hline Qin & $\mathrm{kW}$ & 1738 & 1738 & 1738 \\
\hline Wtur & $\mathrm{kW}$ & 341.2 & 119.8 & 78.8 \\
\hline Wnet & $\mathrm{kW}$ & 220.6 & 97.1 & 54.8 \\
\hline Evaporator area (A) & $\mathrm{m}^{2}$ & 57.9 & 41.1 & 34.8 \\
\hline Preheater area (A) & $\mathrm{m}^{2}$ & 10.9 & 21.8 & 10.9 \\
\hline Condenser area (A) & $\mathrm{m}^{2}$ & 36.5 & 28.1 & 36.5 \\
\hline Ex.dest evaporator & $\mathrm{kW}$ & 34.8 & 36.3 & 60.3 \\
\hline Ex.dest preheater & $\mathrm{kW}$ & 44.6 & 57.6 & 45.6 \\
\hline Ex.dest turbine & $\mathrm{kW}$ & 157.2 & 138.6 & 109.2 \\
\hline Ex.dest condenser & $\mathrm{kW}$ & 445.6 & 472.3 & 480 \\
\hline Ex.dest working fluid pump & $\mathrm{kW}$ & 5.6 & 22.9 & 23.3 \\
\hline Ex.dest cooling tower pump & $\mathrm{kW}$ & 7.5 & 15.2 & 40.3 \\
\hline Total exergy destruction & $\mathrm{kW}$ & 695.4 & 742.4 & 758.7 \\
\hline Exergy efficiency & $\%$ & 54.8 & 48.8 & 44.8 \\
\hline \multicolumn{5}{|l|}{ Cost of System } \\
\hline Turbine & US \$ & 173,540 & 97,098 & 55,310 \\
\hline Evaporator & US \$ & 28,243 & 22,287 & 19,891 \\
\hline Preheater & US \$ & 8,912 & 14,401 & 8,910 \\
\hline Condenser & US \$ & 20,548 & 17,162 & 20,552 \\
\hline Generator & US \$ & 55,153 & 27,829 & 14,104 \\
\hline Total annual cost & US \$ & 58,391 & 36,723 & 24,214 \\
\hline
\end{tabular}

The optimization results using the multi objective genetic algorithm are presented in a curve, as illustrated in Figure 5. Each point is the optimum solution offered by the genetic algorithm method in a Pareto Front curve. Table 6 provides information on the two points (point $A$ and point B) which are located at the end of a series of data plotted in Figure 5. 


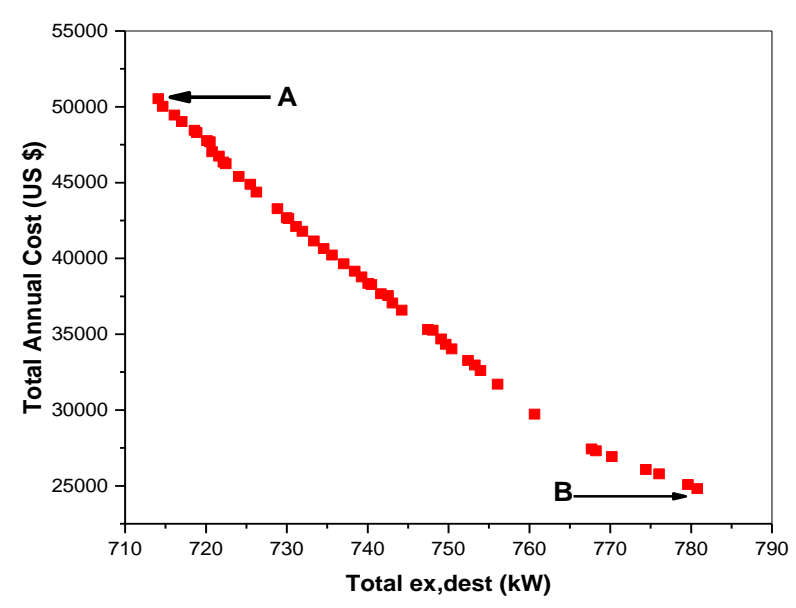

Figure 5 Optimization of binary cycle system using the genetic algorithm

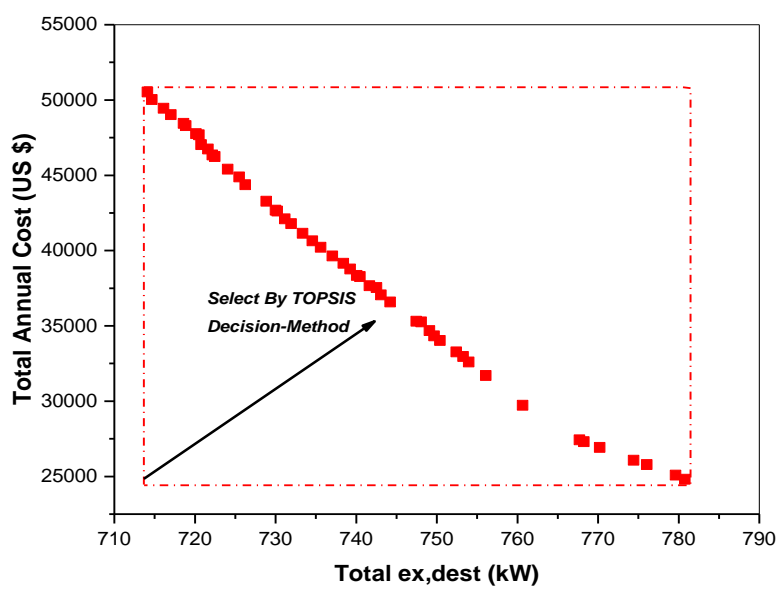

Figure 6 Determination of optimum point from Pareto chart

Table 6 shows that point $A$ is the point at which the total exergy destruction of the system is at its minimum value of $714.11 \mathrm{~kW}$, but at this point the cost incurred for the system reaches its highest level of 50,529 US \$. This point is considered optimum if it is viewed from the perspective of system performance alone, therefore point $A$ is not an optimum point of the two sides (exergy and economy). Furthermore, point B is the point at which the cost of the system at its the lowest, around 25,079 US \$, but at this point the exergy destruction system reaches its highest value of $779.63 \mathrm{~kW}$. So point B cannot be said to be optimum with regard to the two sides (exergy and economy).

Table 6 Optimization results with multi objective genetic algorithm

\begin{tabular}{cccccccc}
\hline & $\begin{array}{c}\mathrm{T}_{\text {evap }} \\
\left({ }^{\circ} \mathrm{C}\right)\end{array}$ & $\begin{array}{c}\mathrm{T}_{\text {obph }} \\
\left({ }^{\circ} \mathrm{C}\right)\end{array}$ & $\begin{array}{c}\mathrm{T}_{\text {owcond }} \\
\left({ }^{\circ} \mathrm{C}\right)\end{array}$ & $\begin{array}{c}\mathrm{P}_{\text {pump }} \\
(\mathrm{kPa})\end{array}$ & $\begin{array}{c}\mathrm{R} \\
(\%)\end{array}$ & $\begin{array}{c}\text { Ex.dest } \\
(\mathrm{kW})\end{array}$ & $\begin{array}{c}\mathrm{TAC} \\
(\mathrm{US} \$)\end{array}$ \\
\hline Point A & 163.3 & 129.9 & 36.3 & 3858 & 29.9 & 714.1 & 50,529 \\
Point B & 163.1 & 129.8 & 35.2 & 3859 & 1 & 779.6 & 25,079 \\
\hline
\end{tabular}

To determine the optimum point of a number of solutions offered by the genetic algorithm, the TOPSIS method is used by making a line that frames the optimum curve. The ideal and non ideal points are then determined as the solution to the selection of optimum value. The optimum value is determined by selecting the most distant point to the non-ideal one and the closet point to the ideal one as illustrated in Figure 6.

The selected point using the TOPSIS method is then selected as the optimum point, which can be seen in Table 7. Table 7 compares the multi objective optimization results (optimum point) with single objective optimization (thermodynamic point and economic point). By using the multi-objective optimization scenario, the optimum operating conditions can be determined. Not only the performance of the system (single point of view) considered, but another point of view, in this case the total annual cost of the system can be also taken into account. The system will be thermodynamically and economically optimum at an evaporation temperature of $163.3^{\circ} \mathrm{C}$, a brine temperature in pre heater outlet of $130^{\circ} \mathrm{C}$, a water cooling temperature at condenser outlet of $35.4^{\circ} \mathrm{C}$, with a working fluid pressure at the pump outlet of $3859 \mathrm{kPa}$ and a composition of the working fluid mixture $86 \%$ R601 and 14\% R744. This is very helpful since both system performance and cost can be estimated based on the input of only five given parameters. 
Table 7 Performance of the system at optimum points on the Pareto chart

\begin{tabular}{lcccc}
\hline \multicolumn{1}{c}{ Parameters } & Unit & Thermodynamic Point A & Optimum Point & Economic Point B \\
\hline $\mathrm{T}_{\text {evapo }}$ & ${ }^{\circ} \mathrm{C}$ & 163.3 & 163.3 & 163.1 \\
$\mathrm{~T}_{\text {bpo }}$ & ${ }^{\circ} \mathrm{C}$ & 129.8 & 130 & 129.8 \\
$\mathrm{~T}_{\text {condo }}$ & ${ }^{\circ} \mathrm{C}$ & 36.3 & 35.4 & 35.2 \\
$\mathrm{P}_{\text {pump }}$ & $\mathrm{kPa}$ & 3858 & 3859 & 3859 \\
Mixed Fraction & $\%$ & 29.9 & 14 & 1.5 \\
System & & & & \\
Wtur & $\mathrm{kW}$ & 129.64 & 119.8 & 73.79 \\
Evaporator area (A) & $\mathrm{m}^{2}$ & 48.6 & 41.1 & 34.9 \\
Condenser area (A) & $\mathrm{m}^{2}$ & 30.1 & 28.1 & 27.6 \\
Total exergy destruction & $\mathrm{kW}$ & 714.11 & 742.4 & 779.6 \\
Exergy efficiency & $\%$ & 50.5 & 48.8 & 46.4 \\
Total annual cost & $\mathrm{US} \$$ & 50,299 & 36,723 & 25,079 \\
\hline
\end{tabular}

\subsection{Effect of Mixed R601 and R744 on Flammability}

The percentage of the R601 and R744 mixture has an effect on flammability. Based on the calculation of Le Chatelier's principle, there is a decline in flammability characterized by an increasing Lower Flammable Limit (LFL) and Upper Flammable Limit (UFL) as shown in Table 8.

Table 8 Effects of R601 and R744 mixtures on flammability

\begin{tabular}{lcr}
\hline \multicolumn{1}{c}{ Working Fluid } & LFL (\%) & UFL (\%) \\
\hline $100 \%$ R601 & 1.40 & 7.80 \\
$98.5 \%$ R601 + 1.5\% R744 & 1.42 & 7.92 \\
$86 \%$ R601 + 14\% R744 & 1.65 & 9.21 \\
$70 \%$ R601 + 30\% R744 & 2.36 & 13.50 \\
\hline
\end{tabular}

Comparison of the lower explosive border and the upper explosive limit on the pure R601 has original value of 1.4/7.8 to 1.65/9.21. Experimental studies were conducted by Kondo et al. (2006). In his research, it found that a hydrocarbon mixture with added $\mathrm{CO}_{2}$ will have an effect on flammability limits which are adequately explained by the Le Chatelier's formula. With the addition of a fraction of R744 to R601, the LFL and UFL values of the mixed working fluid will increase which indicates that the flammability properties of the mixed fluid decrease. This is because the R744 which is a carbon dioxide compound, is an inert gas that affects the combustion reaction, which isolating the oxygen. This will increase the LFL and UFL values of the working fluid mixture until the mixture is no longer flammable.

\section{CONCLUSION}

The study has presented a thermodynamic analysis of the binary cycle system based on modeling and multi-objective optimization. With the help of multi-objective optimization, exergy destruction and total annual cost have been minimized. The decision making method was also used to find the optimal point among a set of Pareto fronts. Based on the optimization scenario, the system has optimum condition at an evaporation temperature of $163.3^{\circ} \mathrm{C}$, a brine temperature outlet the pre heater of $130^{\circ} \mathrm{C}$, a cooling water temperature outlet the condenser of $35.4^{\circ} \mathrm{C}$, while the pumping fluid outflow is about $3859 \mathrm{kPa}$ with a working fluid mixture of 
$86 \%$ R601 and 14\% R744 which has total exergy destruction of $742.4 \mathrm{~kW}$ and a total annual cost of about 36,723 US dollars.

\section{ACKNOWLEDGEMENT}

The authors gratefully acknowledge DRPM Universitas Indonesia for supporting this research with a PITTA Research Grant 2017 No: 817/UN2.R3.1/HKP.05.00/2017.

\section{REFERENCES}

Bejan, A., 1989. Theory of Heat Transfer-irreversible Refrigeration Plants. International Journal of Heat Mass Transfer. Volume 32(9), pp. 1631-1639

Budisulistyo, D., Krumdieck, S., 2015. Thermodynamic and Economic Analysis for the PreFeasibility Study of a Binary Geothermal Power Plant. Energy, Volume 103, pp. 639-649

Chen, H., Goswami, D.Y., Rahman, M.M, Stefanakos, E.K., 2011. A Supercritical Rankine Cycle using Zeotropic Mixture Working Fluids for the Conversion of Low-grade Heat into Power. Energy, Volume 36(1), pp. 549-555

Chen, Y., Lundqvist, P., Johansson, A., Platell, P., 2006. A Comparative Study of the Carbon Dioxide Transcritical Power Cycle Compared with an Organic Rankine Cycle with R123 as Working Fluid in Waste Heat Recovery. Applied Thermal Engineering, Volume 26(1718), pp. 2142-2147

Dai, B., Li, M., Ma, Y., 2014. Thermodynamic Analysis of Carbon Dioxide Blends with Low GWP (Gloal Warming Potential) Working Fluid-based Transcritical Rankine Cycle for Low-grade Heat Energy Recovery. Energy, Volume 64(1), pp. 942-952

DiPippo, R., 2007. Ideal Thermal Efficiency for Geothermal Binary Plants. Geothermics, Volume 36(3), pp. 276-285

Garg, P., Kumar, P., Srinivasan, K., Dutta, P., 2013. Evaluation of Carbon Dioxide Blends with Isopentane and Propane as Working Fluids for Organic Rankine Cycles. Applied Thermal Engineering, Volume 52(2), pp. 439-448

Kondo, S., Takizawa, K., Takahashi, A., Tokuhashi, K., 2006. Extended Le Chatelier's Formula for Carbon Dioxide Dilution Effect on Flammability Limits. Journal of Hazardous Materials, Volume 138, pp. 1-8

Longo, G.A., Mancin, S., Righetti, G., Zilio, C., 2015. A New Model for Refrigerant Boiling Inside Brazed Plate Heat Exchangers (BPHEs). International Journal of Heat and Mass Transfer, Volume 91, pp. 144-149

Lubis, A.' Jeong, J., Giannetti, N.Yamaguchi, S., Saito, K., Yabase, H., Alhamid, M.I., Nasruddin, 2018. Operation performance enhancement of single-double-effect absorption chiller, Applied Energy, Volume 219, pp. 299-311

Nasruddin, Lemington, Alhamid, M.I., 2015, Numerical simulation of a two-bed solar-driven adsorption chiller in a tropical climate, International Journal of Technology, Volume 6 , pp. 594-603

Nasruddin, Alhamid, M.I., Daud, Y., Surachman, A., Sugiono, A., Aditya, H.B., Mahlia, T.M.I., 2016a. Potential of Geothermal Energy for Electricity Generation in Indonesia: A Review. Renewable and Sustainable Energy Reviews, Volume 53, pp. 733-740

Nasruddin, Sholahudin, S., Giannetti, N., Arnas, 2016b. Optimization of a Cascade Refrigeration System using Refrigerant $\mathrm{C}_{3} \mathrm{H}_{8}$ in High Temperature Circuits and a Mixture of $\mathrm{C}_{2} \mathrm{H}_{6} / \mathrm{CO}_{2}$ in Low Temperature Circuits. Applied Thermal Engineering, Volume 104, pp. $96-103$

NIST Standard Reference Database 23 Version 9.1, 2013. NIST Thermodynamics and Transport Properties of Refrigerants and Refrigerant Mixtures. REFPROP 
Pambudi, N.A., Itoi, R., Jalilinasrabady, S., Jaelani, K., 2014 Exergy Analysis and Optimization of Dieng Single-flash Geothermal Power Plant. Energy Resources Engineering, Volume 78, pp. 405-411

Prasetyo, B.T., Himawan, Suyanto, Surana, T., Agustina, L., Yasser, R., 2010. Design and Testing of n-Pentane Turbine for $2 \mathrm{~kW}$ Model of Binary Cycle Power Plant. In: Proceedings World Geothermal Congress, Bali, Indonesia

Sachdeva, R., 2006. Fundamental of Engineering Heat and Mass Transfer (SI Unit). New Age International Publisher

Taylor, L.J., 2015. Development of Low-Temperature Geothermal Organic Rankine Cycle Standard. Master Thesis, University of Canterbury

Wu, C., Wang, S., Jiang, X., Li, J., 2017. Thermodynamic Analysis and Performance Optimization of Transcritical Power Cycles Using $\mathrm{CO}_{2}$-based Binary Zeotropic Mixtures as Working Fluids for Geothermal Power Plants. Applied Thermal Engineering, Volume 115, pp. 292-304 